\title{
Does Athletics Undermine Academics? Examining Some Issues
}

\author{
Robert L. Simon \\ Hamilton College
}

When I was a graduate student at the University of Pennsylvania in the late 1960s, philosopher Paul Weiss (1969) published his ground-breaking book, Sport, A Philosophic Inquiry. I distinctly remember a review of the book from The New York Times being posted on the graduate student bulletin board under a sign with very large letters that said, "Write on this subject only if you already have tenure."

In retrospect, the attitude expressed by the sign conveyed a narrowness that characterized a good deal of the academic philosophy of the time. After all, sport was an important part of the culture, surely worthy of study, and involved interesting philosophical issues ranging from the conceptual, such as analysis of the nature of sport, to the ethical, such as the proper role of athletics in colleges and universities. It has been heartening to see more and more scholars become engaged with issues raised by sports and now helping to launch a project, initiated by the NCAA, to rigorously study intercollegiate athletics.

The existentialist philosopher Albert Camus once remarked that the context in which he really learned ethics was that of sport (Camus, 1960). Even if Camus learned valuable moral lessons from sport, it doesn't follow that intercollegiate athletics is, can be, or should be a medium for moral education. Indeed, some critics will argue for the moral bankruptcy of intercollegiate athletics, citing such examples as academic fraud in one major basketball program, falsification of academic records to insure eligibility for an athlete at another, misbehavior including alleged criminal acts by some recruited athletes, and dismal graduation rates in some high visibility men's programs. Nonetheless, it is important to remember that intercollegiate sports occur at a wide variety of institutions, ranging over different divisions and different educational missions. The problems of some high-profile Division I programs, particularly in men's high-visibility sports, are not always typical of the wide variety of intercollegiate programs found across the nation.

My remarks will have three main goals. First, I will argue that a reasonable case can be made that in some contexts, intercollegiate athletics and academics not only do not conflict but may be mutually reinforcing. Second, I will suggest that some of the criticisms of such a view are at best indecisive and in some cases rest on highly debatable assumptions that may well apply to some areas of intercollegiate sports but probably not to all. Third, in discussing these critiques, I attempt

The author is with the Philosophy Department, Hamilton College, 210 College Hill Road, Clinton, NY. 
to identify further research that needs to be done to allow for a fuller assessment of the relationship of academics to intercollegiate athletics. Along the way, I will try to disentangle and identify the sometimes unacknowledged normative assumptions that also underlie much of the discussion.

\section{Athletics as a Mutual Quest for Excellence Through Challenge}

Let me begin by considering how intercollegiate athletics, in at least some of its manifestations, might contribute to the educational and moral growth of participants. Of course, many observers are sceptical about whether athletic competition has any value whatsoever in practice, or even in theory. However, a number of writers on ethics have developed similar views on not only what presuppositions must be satisfied to promote athletic competition that is ethical but that also might promote opportunities for education and moral growth. Competitive sports, on such a view, are governed by constitutive rules that create challenges to the participants, challenges that, when well designed, test the physical and mental qualities of the competitors (Suits, 1973). ${ }^{1}$ Athletic competition, when conceived of in this way, is not only ethically defensible but often admirable when entry into the contest is freely chosen, when opponents are viewed as facilitators with certain rights and duties rather than as mere obstacles to be beaten down, and when respect is shown to the values inherent in the game. ${ }^{2}$

The most important implication of this conception for our purposes is that athletic competition, when it fits or resembles this model, incorporates values that parallel and can reinforce primary academic values. On this view, engagement in athletic competition encourages the development of certain moral and educational virtues among competitors and also illustrates and reveals them to a wider audience. A different line of argument, defended recently by Myles Brand, argues that athletic contests are relevantly similar to such performances in the arts as dance and musical recitals that already are regarded as academic (Brand, 2006).

For example, success at athletic competition conceived of in this way requires dedication and commitment, intellectual honesty about one's strengths and weaknesses and those of opponents, willingness to accept failure and learn from mistakes, respect for the deepest values of the sport in question, and acknowledgment and conformity to norms of fair competition. Moreover, as Drew Hyland and others have maintained, athletic competition has a kind of critical dialogic structure where opponents decide how to react to each other's actions and strategic decisions and afterward subject such choices to critical scrutiny. In the process, they have opportunities to gain self-knowledge about their capacities and character including their ability to learn from mistakes and consequently improve and develop (Hyland, 1984).

If this view has force, it supports the idea that academic values and athletic ones can be mutually reinforcing. While it may best fit many Division III and other nonscholarship institutions, such as those of the Ivy League, that maintain that their athletics program has significant educational components, it also may have value for any educational institution that is attempting to better integrate athletics and academics. 
Let us call the claim that the values of intercollegiate athletics, properly conducted, can harmonize with and support sound academic and moral values the Mutual Reinforcement Thesis. This thesis can be understood in a variety of ways. For example, it might be making a causal claim that participation in athletics leads to moral and academic growth on the part of participants or perhaps some wider group, such as spectators. However, it also can be understood as making different sorts of claims. For example, the thesis might be understood educationally, in that athletic competition may be held to reveal or illustrate and express values that are important in academics as well, such as the value of working together with different sorts of people, and of dedication and commitment. Additionally, the thesis can function critically by providing standards of evaluation that can be applied to academics and athletics.

Thus, the example of a team playing well below its potential because of the selfishness of its players, or because of ideological or ethnic splits among them, may reveal and illustrate the dangers of allowing such differences to undermine common goals as well as provide grounds for criticizing the inability of the players to set aside differences for a common cause. A similar point can be applied to ideological differences in academic debate that result in each side demonizing the other, thus undermining the common goal of intellectual discourse and reasoned dialog. (The point, of course, is not that all differences should be papered over in the name of teamwork but rather that failure to deal reasonably with difference often will have unacceptable costs.) Or a professor might point out to studentathletes that their ability to respond to criticism and learn from their mistakes on the field also would pay dividends if they reacted similarly to criticism from their classroom instructors.

However, the Mutual Reinforcement Thesis is open to criticism from a variety of quarters. By examining some of these criticisms, perhaps we not only can come to a reasonable assessment of the thesis but also identify issues that need to be clarified by further inquiry in areas where both normative and empirical issues are interrelated.

\section{Three Criticisms of Mutual Reinforcement}

\section{1) College Athletics Undermines Critical Thinking}

According to the first sort of criticism I will examine, intercollegiate athletics does not in fact teach values that reinforce or cohere well with central academic values. According to proponents of this view, whatever is the case in theory, participation in intercollegiate athletics undermines rather than reinforces critical thinking.

Thus, Peter French, in his recent book Ethics and College Sports (2004), has argued that dominance by often authoritarian coaches tends to produce athletes who do not think for themselves but who learn simply to obey commands of their coaches and follow strategies the coaches lay down in advance. French cites intercollegiate football as an example of a sport "where every play and virtually every move of every player is directed by the head coach and a vast array of assistant coaches for every aspect of the game. Players, at best, are learning to follow orders and, I suspect, the consequences of not doing so" (French, p. 52). In other words, in the 
actual world of intercollegiate athletics, players are trained to suppress critical or strategic thinking rather than engage in it.

However, while some coaches may fit French's account, he provides little if any support for the claim that "very few" take seriously their role as moral model. His description of coaching may seem to fit football best, but even here questions can be raised. French sees coaches as replacing the players' autonomy by taking over the game and calling all the plays. However, football arguably involves constant decisions by players even in the most controlled offense. Football coaches I have talked with about this topic all mention the ability to make good decisions under pressure as among the most important assets a player can have. Of course, different football coaches may have very different styles of teaching and actual practices may vary between the athletically elite football institutions and small liberal arts colleges in Division III of the NCAA. In addition, more strategic decision making may be called for at some positions than others. Nevertheless, I suspect French's picture of the football coach is significantly overdrawn. Further research, however, would surely shed light on how many head football coaches stress good decision making on the field, as well as how many give their players opportunities to exercise their own strategic skills, including encouraging input by players into decisions about team strategies.

If the picture of the coach presented by French is questionable when applied to football, it can be made to fit other sports only with even greater difficulty. Individual sports, as I believe French would acknowledge, such as tennis, golf, and squash require constant decision making by the player. Basketball, although a team sport, requires players to recognize defenses, see and quickly exploit weaknesses in the play of opponents, and make the best responses appropriate to specific game situations. Similar points can be made about other team sports such as soccer, lacrosse, and softball. Surely, one of the most important and satisfying tasks of the coach in such sports is to teach players how to think about the strategy of the game and to make appropriate decisions given the context in the athletic contest.

Moreover, the issues raised by French's comments go beyond the empirical. How much authority should the coach have? Indeed, we might wonder whether any sharp contrast between the supposedly authoritarian coach and the autonomyminded faculty can be justified. Faculty use their authority to select texts, pick subjects for discussion, and organize their courses often without student input but are not regarded as authoritarian. Some faculty, a small minority I hope, are caustic and sometimes demeaning to students and advisees. Although coaches may sometimes get angry at players, and sometimes cross the line of what should be tolerated, often this behavior could be because they, like other good teachers, simply want their athletes to develop their potential to the fullest.

Thus, although French's criticism might be justified in particular contexts, we should question the view that intercollegiate athletics as a whole discourages or does not involve critical thinking. Further work needs to be done both to find out what coaches actually do, whether what they do varies by sport or divisional affiliation or philosophy of the institution, and normatively to explore what degree of strategic autonomy should be ceded to players and what the role of the coach as decision maker should be. For example, it normally is unreasonable to require a democratic vote during a time out in the closing seconds of a tied basketball game as to what play the team should run. In special cases, however, things might be 
different; consider the championship game in the movie Hoosiers when the coach, played by Gene Hackman, changes his own strategy and follows the suggestion of his players in designing the final game winning play.

\section{2) Intercollegiate Athletics and Moral and Cognitive Development}

French also raises another kind of objection, directed specifically at the idea that intercollegiate athletes provides a kind of moral education promoting such values as fair play and respect for the opponent. According to this line of argument, and contrary to the causal version of Mutual Reinforcement, college athletes do not internalize the kinds of values in sport that might reinforce parallel values in academic or ethical thinking. As he points out, this objection can take two forms, and I would add a third version as well.

The first version simply denies that athletes generally develop morally as a result of their participation in athletics. In more extreme forms, this version maintains that, in fact, sport might hinder moral development or even promote bad character and moral regression rather than growth. The work of a number of investigators on the effect of sport on moral development might be cited in support of such skepticism, for example, the work of Jennifer Beller and Sharon Stoll, and David Shields and Brenda Jo Bredemeier. Stoll and Beller claim, for example,

Nonathletes use a significantly more principled and less calloused approach to addressing moral issues both in the sports arena and in societal contexts . . . Forty years of research, conducted by more than 20 researchers studying tens of thousands of athletes and non-athletes from youth, high schools, collegiate and Olympic levels, simply does not support the notion of sport as a character-building activity, particularly as it applies to sportsmanship behaviors and moral reasoning ability. (Stoll \& Beller, 2000, as quoted in French, 2004, p. 54)

French himself expresses some sympathy for the idea that "there are certain morally good virtues and values in sports participation" but doubts whether they transfer to the behavior of athletes once they leave the playing field (French, p. 55).

The second version of the objection acknowledges that athletes might internalize positive values through their participation in athletics but denies these values transfer to behavior off the playing field.

The third version also recognizes that athletes often exhibit positive values, such as the ability to work well with others or to respond well to criticism, and may bring some special benefits to their careers and communities after college, such as a capacity for teamwork and intensity and drive, but attributes all this to preselection. In other words, such qualities are a cause of success in athletics rather than a result.

Consider the first version of the claim that participation in competitive sport, particularly intercollegiate athletics, does not build character or contribute to moral or intellectual growth. While it certainly seems plausible to think that under some actual conditions participation in athletics can not only fail to promote the development of good character but also encourages bad behavior, questions can be 
raised about whether the empirical research justifies broad generalizations about the role of sport and moral development. Before turning to such issues, however, it is important to distinguish the Mutual Reinforcement Thesis from the bald assertion that participation in sport, including intercollegiate athletics, builds desirable moral character.

The Mutual Reinforcement Thesis (the thesis that academic and athletic values are or can be mutually reinforcing) is actually a family of related claims, only one of which is a causal thesis about the effects of intercollegiate athletics on participants. In addition, on noncausal interpretations, it might claim that athletic competition often reveals and expresses desirable values, that such values cohere well with academic values, and can serve as the basis for criticism of morally and educationally dubious practices in both athletics and in the classroom. Even in the causal version, proponents of mutual reinforcement should acknowledge that whether morally acceptable values are reinforced in athletics and whether they transfer to other areas depends on contextual factors, that is, on how sport is practiced in a specific setting. For example, star athletes may develop a sense of entitlement and privilege that leads them to regard themselves as exempt from ordinary standards of behavior. Too often, they end up acting in unacceptable ways, perhaps in part, because of the adulation they received as a result of their feats on the field of play.

We also need to distinguish the claim that participation in athletics promotes general moral growth, or ability at sophisticated moral reasoning, from the more restricted claim that it reinforces specific values, perhaps including those relevant to academics. For example, it is conceivable that participation in athletics in many contexts does not promote skill in abstract moral reasoning but does make participants more open to criticism and more willing to recognize and appreciate achievement by others than otherwise would be the case. Or, as James Q. Wilson recently has suggested, athletic teams are one of the relatively few associations in American society that often are successful in combing diversity with elements of "social capital" as trust and cooperation in pursuit of a common goal. Wilson makes this suggestion in his discussion of Robert Putnam's Bowling Alone (2000) and of Putnam's more recent work on the possible conflict between the pursuit of diversity and social capital (Wilson, 2007). So even if participation in intercollegiate athletics does not promote general moral growth or sophisticated moral reasoning, it could have a narrow positive effect in supporting and revealing more specific values closely tied to meeting the challenges of competition in sport.

Having said that, the empirical research on the relationship of participation in athletics and moral development is important and deserves serious consideration. Much of it involves presenting respondents with moral issues or dilemmas and assessing their responses. I cannot survey that extensive literature here, but I will try to raise some philosophical concerns about its presuppositions that might suggest fruitful future lines of inquiry about athletics and moral development.

First, philosophers rightly will worry whether the different researchers in the area all have the same conception of moral development. Those who take a virtue-based approach might be looking for quite different things, for example, than those who adopt Kohlberg's view of moral development as requiring skill in applying impartially justified abstract principles to moral dilemmas. In other words, different researchers might be investigating quite different issues, because 
they mean different things by moral character or moral development. As a result, general conclusions about the effect of participation in athletics on moral growth may be difficult to draw.

A second and related point is that the researcher's own theory of what is ethical may influence findings, and indeed sometimes may itself be controversial. For example, consider the following sample question from the Hahm-Beller Values Choice Inventory (HBVCI) used by Stoll and Beller (2000) in their investigations of moral development. In discussing this question, my point is not to undermine the research of which it is part, which probably couldn't be done by considering only one question, but to indicate how scoring of responses can involve both empirical and evaluative elements that need to be disentangled, and hence, why the significance of the results might be open to interpretation.

Certain basketball teams are coached to run plays that cause the opponents to foul. Players and coaches believe this is a clever strategy because the opponents may foul out of the game, giving their team an advantage. Because the coach orders this type of play, the players should follow his directions. (University of Idaho Center for Ethics, 2008)

I suggest, however, that just which response to this question is ethically justified is quite controversial. For example, although we should want to test ourselves in competitive athletics by matching our primary skills (the skills that are central to excellence in the sport such as dribbling, shooting, and passing the ball) against the best the opposition has to offer, strategic skills also are part of the test constituted by sport. Such skills, including knowing how to avoid fouling on defense, also are fundamental and help define what counts as meeting the test or challenge of the contest. In the latter view, the coaches' decision is just good strategy and not morally controversial. Similarly, it is just good strategy in baseball when, with the game on the line, the manager sends in a left-handed relief pitcher to face the opposition's best left-handed batter rather than sticking with his right-handed ace hurler. Part of the test of baseball is for hitters to be able to bat successfully against both right- and left-handed pitchers, or for a team to have enough depth to counter the pitching change with a skilled pinch-hitter. In other words, just what counts as bad sportsmanship in meeting the test of excellence can itself be morally controversial. Athletes who sometimes give what is considered the morally less mature or sensitive answer may have a plausible moral argument supporting their conclusion even if they do not always articulate it well.

Critics might argue that even if my analysis of this question is correct, it may not be typical of questions on the HBVCI or other types of surveys used by different investigators. Perhaps so, although my discussion that follows of the obligation of athletes to report bad calls in their favor by officials suggests that at least some other sample questions also raise debatable issues. In any case, I suggest later in the paper that interdisciplinary discussion among interested ethicists, sports psychologists, and sociologists on issues raised in scoring test results is likely to be productive.

It might be replied that what is evaluated is not the answer to the question but the sophistication and cogency of the moral reasoning supplied in its defense. For example, the question may be designed to investigate whether athletes blindly follow morally controversial instructions from a coach. If the justification for the 
strategy sketched above is at all cogent, however, athletes may have no good reason to regard the proposed strategy as morally questionable in the first place.

Moreover, at least some ethicists will have doubts as to whether identification of more and less sophisticated forms of moral reasoning is itself controversial. For example, Kohlbergian cognitive psychologists tend to regard deontological reasoning from abstract universal principles that can be impartially upheld as perhaps the most sophisticated form of ethical reasoning. However, this would surely be contested, not only by sophisticated utilitarian theorists, but by virtue ethicists and proponents of an ethic of care who stress good judgment in concrete instances rather than abstract reasoning (for an earlier discussion that raises some similar points, see Gough, 1995). Indeed, there may be a bias among investigators toward liberal political theorists such as Kant and Rawls. As a result, some researchers may give too little weight to social values such as teamwork and its contribution to community, as well as the capacity to set aside differences and work with diverse others toward a common end. I would argue that the work of Kant and Rawls goes a long way toward defending the principles that are fundamental to the liberal democratic state but suggest that we should not thereby exclude the values of community and social association from our moral universe.

What about participation in intercollegiate athletics and moral responsibility? It is sometimes claimed that athletes tend to be morally calloused in the sense that they transfer the burden of moral decision making "from their shoulders to those of officials, the enforcers of the rules, and to coaches, whom the players learn to see as responsible for all decisions." French remarks that "there is something eerily reminiscent of the famous Milgram experiments" in the deference shown by athletes to coaches and officials (French, 2004, p. 53).

But is this all too quick? In the Milgram experiments, subjects were asked to inflict apparent harm upon seemingly helpless people against their will while an athletic contest presumably is a voluntary activity conducted under conditions of rough equality of power. Officials are not ordering players to inflict harm on the helpless but are enforcing rules that all have implicitly agreed to follow. Second, it is doubtful if the conclusion applies to all sports. For example, individual sports such as golf do require players to make calls against themselves when they violate rules.

In addition, it may be difficult to decide just when athletes should attempt to substitute their own judgment for that of officials and coaches. Perhaps, to use an example used in the HBVCI, a volleyball player who touched a ball that the official incorrectly calls out should report to the official that she touched the ball. But things may not always be that simple. In basketball, a player may think she has fouled an opponent but perhaps the official has a different conception of what constitutes improper contact, or regards the contact as inconsequential ("no harm no foul"), or the player is not certain of what happened. If players constantly try to correct officials in such situations, they well might be disrespecting the official's judgment and experience or, simply, be viewed as trying to "show up" the referee. Indeed, it's not even clear whether it is the individual beneficiary of the bad call who should unilaterally confess or whether teammates and coaches ought to be consulted as well.

I'm sure we can think of particular cases where attempting to correct a bad call in our favor is morally appropriate or even required. However, the general 
rule that players leave the officiating to officials may be the one athletes generally ought to follow, in part because they may not be very good at picking up the perhaps few incidents where they ought to acknowledge a self-violation and in part because their own judgment often may be no more accurate than that of trained rules officials themselves. So while I myself do think that more attention ought to be given to the obligations of athletes to enforce the rules-maybe team sports should be more like golf - it isn't easy to say what the principles that apply in this area should be. Without clear guidelines, athletes are not necessarily adopting a morally immature stance by leaving officiating to the officials, at least in the vast majority of instances.

This leads to another formulation of the view that participation in intercollegiate athletics fails to promote moral growth or education; namely, the idea that whatever values are promoted on the field do not transfer to activities away from it. On one version of this account, athletes bracket ordinary morality while on the playing field and adopt a separate set of moral rules peculiar to sport. One can tackle an opponent on the football field but not on the street after a game. So even if athletes learn something about some special sports morality through athletic competition, it is questionable if this transfers to growth in ordinary moral thinking or judgment.

This issue of bracketing ordinary morality in special contexts does raise complex issues but they are not restricted to sport. For example, college professors normally have the right to decide who can speak for how long during class, and even when to cut off discussion and resume a lecture, but they have no such right in many other areas. Does this promote a special morality of the classroom, in which students learn to defer to the authority of the professor, but which has no application in other contexts? Or does it promote respect for the broadly applicable principle that critical dialog must be structured to allow for a variety of reasonable voices to be heard?

In the absence of a convincing argument to the contrary, the common sense position that life is not divided into a multitude of totally separated compartments but rather that lessons learned in one area of endeavor often carry over to another is intuitively plausible. Thus, philosophy professors expect that their efforts to teach students to think logically might have some influence on the ability of their students to analyze various forms of argument outside of class.

I suggest, then, that the burden of proof should lie with those who question the transferability of values from one domain to another. Even if that point is mistaken, however, a second point may have even more force. That is, it is questionable whether a special morality of sport is totally separate from ordinary forms of moral thinking. For example, the convention in soccer that the team in possession of the ball should not take advantage of an opponent's injury but instead should halt play by kicking the ball out of bounds surely reflects ordinary notions of fairness and is not some special part of an alien ethic applying only on the field of play.

In other cases, what looks like an instance of a special morality of sport may simply be the application of a more general universal moral principle to athletics.

In this regard, Brenda Jo Bredemeier and David Shields most recently have characterized moral maturity as involving balancing of common and mutual interests, in which each party considers the values and points of view of the others, in trying to reach harmony of or at least compromise of interests. (See, for 
example, Bredemeier \& Shields, 2001.) But, attractive as such a suggestion may be, we need to be careful about the level at which such reconciliation takes place. Is the level that of each individual action or the level of acceptance of the practice within which the acts take place? A hard tackle in football may at one level fail to equally advance the interest of all the players but may be acceptable morally, if at a more fundamental level all players have freely entered the game of football with the knowledge that hard tackles are part of the game. Robert Fullinwider (2006) makes a similar criticism of Bredemeier and Shields. We also need to keep in mind Brian Barry's (1995) reminder in his defense of justice as impartial reasoning; namely, that justice as impartiality does not require we be impartial whenever we make a decision but that the general rules and principles under which we operate (that may sometimes allow us to be partial, for example, in paying special attention to our own children) be impartially acceptable to all.

Thus, to argue that athletes tend more often than nonathletes to bracket ordinary moral principles by egoistically putting themselves or their team first may not give adequate weight to a higher level consensus among athletes that acknowledges such a focus as universally acceptable in the context of competitive athletics. While I agree that it is a sign of moral impoverishment if athletes view athletic competition merely as a kind of Hobbesian war of all against all, a focus on winning and on one's own team's competitive success need not be an expression of such a Hobbesian view. Might it not instead sometimes be a reflection of a higher order agreement imposing obligations on all to play to win so that each participant or team can be rigorously tested in intense competition? If so, it is likely that in at least some cases, context-dependent moral principles that apply in sport may be justifiable by appeal to more general context-independent principles that apply across the board to moral thinking.

The transferability objection then faces two key criticisms; that the degree of separation between areas of human endeavor that it assumes is questionable, and that the separate morality of sports it postulates is not so separate after all.

Finally, what about the third version of the objection based upon preselection? According to the preselection argument, athletes may indeed possess certain virtues, such as drive, ability to cooperate with others, and the capacity to learn from failure and from criticism, but this is not the result of their participation in athletics. Rather, it is among the causes of their success as athletes (Shulman \& Bowen, 2001, p. 97).

In assessing this argument, note that if sound, it applies to far more than athletics. For example, why assume the education provided by more selective colleges and universities has any major effect on students? After all, those institutions select through the admission process the very students who have already demonstrated their ability to succeed in the classroom. So if preselection applies to athletics, why not to academics as well?

I suggest that on the contrary, in the absence of a convincing argument for preselection, the common sense position I will sketch is the default position that applies in both areas. According to this position, admissions officers and athletic recruiters each endeavor to select candidates who have demonstrated they possess the virtues needed for success in their respective areas. However, both the academic and athletic experiences of such individuals in college contribute to their development in both areas by building upon and enhancing skills and capacities they already 
possess. Indeed, some develop significantly in each area. Thus, until we are given not just a theory but a compelling argument that preselection is virtually the whole story, we should resist the claim that the college experience adds nothing to what students, athletes or not, already bring to the table upon entering college.

Before concluding this section, it is worth noting that a number of researchers in this area refrain from making broad generalizations about the effects of participation in intercollegiate athletics on cognitive and moral development. In their recent work, for example, Bredemeier and Shields recognize the complexity of the issues they discuss. Thus, in one recent article, while they report that in comparing a sample of college basketball players to nonathletes (the moral reasoning of the nonathletes was significantly more mature than was that of the athletes), they also note that the moral reasoning of females about sport was more mature than that of males. To complicate things still further, when intercollegiate swimmers were added to the study, the moral maturity of swimmers and nonathletes did not differ (Bredemeier \& Shields, 2001).

Perhaps because of such diverse results, Bredemeier and Shields (and I think Stoll and Beller would agree) acknowledge that the so-called moral maturity of athletes may differ according to all sorts of variables, including gender, whether sports are individual or team oriented, and perhaps the philosophy of the coach and institution, and maybe even the divisional level of the NCAA in which the sport is played. Indeed, Bredemeier and Shields conclude, sensibly in my view, that "generalizations about sport involvement and moral character are not warranted" and, in another venue, that "the influence that sport has for its participants depends on a complex set of factors tied to the specific sport, and the social interactions that are present (Bredemeier \& Shields, 2001, p. 7; see also Bredemeier \& Shields, 1995, p. 195). Thus, as I think Beller and Stoll also would agree, how well academic institutions integrate athletics and academics may have a significant effect on the educational and social benefits athletes derive from their experience in intercollegiate athletics.

To summarize this section, many of the studies of the effects of participation in athletics on moral and intellectual development raise disturbing questions for advocates of Mutual Reinforcement. However, such studies may often rest on assumptions that are themselves moral in character and which may sometimes be controversial in their own right. ${ }^{3}$ Thus, the extent to which research on moral development of athletes is purely empirical is debatable. This entanglement of the empirical and the normative constitutes an area where social scientists and ethicists can each contribute to identify and resolve problems that are neither entirely factual nor entirely evaluative and that provide fertile ground for interdisciplinary investigation.

\section{3) Athletes and Academic Performance at Selective Institutions ${ }^{4}$}

A third line of criticism challenges mutual reinforcement by arguing that at selective colleges and universities, including liberal arts colleges where athletes can make up as much as $30-40 \%$ of the student population, declining academic performance by student-athletes negatively affects the entire academic climate of the institution. This has been argued by James L. Shulman and William G. Bowen 
in the influential book, The Game of Life (2001), and more recently by Bowen and Sarah A. Levin in its sequel, Reclaiming the Game (2003), which focuses especially on the New England Small College Athletic Conference (NESCAC), to which my home institution, Hamilton College, belongs, and on the University Athletic Association (UAA).

These books do not directly contradict the thesis that academic and athletic values can be mutually reinforcing. In fact the authors sometimes lament the decline in academic performance of student-athletes from the 1950s and 60s when they equaled or outperformed nonathletes academically at the institutions in the study. However, the argument of the books is that even at the most selective liberal arts institutions that claim to integrate athletics and academics, a significant and growing proportion of more recent cohorts of student-athletes have not internalized academic values and may subordinate academic achievement to achievement of goals in athletics. Although the majority of institutions in the study are highly selective and may not be representative of higher education generally, these studies are important because one might argue that if intercollegiate athletics as we know it does not harmonize with academics at such schools, harmonization cannot reasonably be expected anywhere else.

The argument of these books is largely statistical, drawing on an extensive database involving cohorts of graduates from the highly selective schools in the sample. The institutions covered in the studies include liberal arts colleges such as Williams, Swarthmore, Denison, and Hamilton, as well as several Ivy League schools and a number of academically respected but athletically elite universities such as Duke, Washington University, and Penn State. The same database also was the foundation for another widely cited study, The Shape of the River (Bowen \& Bok, 2000) in which Bowen and former Harvard President Derek Bok defend affirmative action admissions programs by reporting on the social contributions of alumni beneficiaries of such admission policies.

While my concern is not primarily with the statistical analysis in The Game of Life, I do find the statistical argument intriguing but also less than conclusive. This is because of questions the study leaves unresolved which, if examined further, might yield data that at least would soften the study's rather harsh evaluation of the academic performance of athletes. Perhaps some examples will illustrate my concern.

Thus, to get a true picture of the effect of athletics on academics, don't we need to count the excellent students who would not have attended an institution if not for its athletic program, as well as recruited athletes who perform poorly in the classroom? Unfortunately, The Game of Life does not consider in depth whether outstanding students (athletes and nonathletes alike) might be attracted to an institution because of its athletic program, either because they enjoy involvement in athletics even as spectators or because athletics has enhanced the overall visibility of the institution they attend. This was brought home to me in a seminar a few years ago when, after I had described the thesis of The Game of Life, a female three-sport athlete and absolutely outstanding student remarked, "I never would have come here if I hadn't been a recruited student-athlete." Moreover, the evidence here is not merely anecdotal. For example, a self-study at my own institution indicates that recruited athletes, even in high profile male sports, are very well represented among those receiving academic awards at graduation and that "female recruited 
athletes had, by a significant amount, the largest percentage of summa cum laude graduates than any group" (From "Athletes and Academic Performance," a summary report prepared at Hamilton College in 2004 and quoted with permission of the College.)

To cite just one more concern with the book's statistical argument, perhaps many athletes, who come to college with the idea that they are there primarily to play sports, do poorly at first and, as a result, end up with worse overall records than students at large. However, many such student-athletes may mature intellectually during their college years and end up working at a similar level to other students by the time they graduate. Perhaps in some cases the qualities of discipline and hard work they acquired through athletics, and the encouragement of their coaches, have contributed to such gains. An issue that calls for further investigation, then, is whether the academic performance of student-athletes improves as they become juniors and seniors, so that even if their overall class rank remains lower than that of their peers, the differences become less and less and perhaps even vanish over time.

Remember also that even according to The Game of Life, female athletes perform about as well academically as other female students, a significant number of teams at many of the institutions studied do as well or nearly as well in the classroom as other students, and athletes graduate at as high or higher rate than students at large. Hence, the picture of the academic performance of athletes at the institutions studied is far from all bleak, a point that might be lost if only the negative findings of the book are emphasized.

Perhaps of greater interest in this forum than debates about the interpretation of statistics are questions both about the explanation Bowen and Shulman provide for their conclusions and about whether they have correctly assessed the value of athletic programs at the schools in their study.

What explains the alleged weak performance of male student-athletes at institutions examined in The Game of Life? Bowen and Shulman attribute much of the fault to what they call a "culture of sports" (Shulman \& Bowen, 2001) pp. 74-86). While this culture is not precisely defined, it involves a tendency to socialize mainly with other athletes, pursue certain majors in proportions different from the rest of the student population, accept more conservative values than other students, and be more focused on financial success after college than other students. This culture of athletics has been fostered by the early specialization of youngsters into particular sports, recruiting policies by admissions officers that reward such specialization (the search for a well-rounded class rather than wellrounded individuals), and consequent estrangement of athletes from the academic mission of their institutions.

This hypothesis is not implausible if presented as a partial explanation. But is this explanation likely to be the whole story? Before we come to any firm conclusions, don't other possible explanations also need to be considered? For example, do faculties that arguably have increasingly become less and less involved with student life exhibit an increasing indifference or insensitivity to or, in more extreme cases, even disdain for the athletic involvement of students? Does this in turn reinforce withdrawal by athletes into their own culture? Shulman and Bowen have found that athletes with faculty mentors outperform other athletes academically (2001, pp. 71-74), but do such attitudes, to the extent they are in fact exhibited, 
create obstacles to the development of such a relationship? To their credit, Shulman and Bowen briefly consider the possibility of faculty disdain for athletes or even prejudice against athletes as a possible explanation for the alleged poor academic performance of student-athletes but acknowledge they have no way to analyze possible effects statistically. I myself seriously doubt if very many faculty, whatever their personal feelings about athletics, actually grade athletes unfairly. What may be more likely, however, is that some faculty express a kind of insensitivity or even hostility to athletics that may discourage student-athletes from coming to them for help at the first sign of academic trouble. For example, an athlete who, because of a conflict with a scheduled contest, misses a class with a professor regarded as unsympathetic to athletics may be more hesitant than other students to go to that faculty member for help, perhaps especially if the student-athlete is the first family member to attend a university and, as a first year student, feels less comfortable with faculty than other students who are more at ease in an academic climate.

In the later work, Reclaiming the Game, Bowen and his coauthor Sarah A. Levin consider at somewhat more length a different alternative hypothesis, what they call "stereotype threat." According to Stanford psychologist Claude Steele who originally proposed the idea, "Members of certain minority groups are prone to under-perform academically because of an unconscious fear of living up to negative group stereotypes" (as quoted in Bowen \& Levin, 2003, p. 235). Bowen and Levin acknowledge that "stereotyping [of athletes] can be real and it may well take a toll academically" (Bowen \& Levin, p. 235) but again acknowledge they have no way of assessing its impact.

The point of Steele's theory is that the stereotyping may be internal, coming from the athletes themselves. So just as a golfer who visualizes a bad outcome to a shot may hit the water hazard instead of the green, athletes who doubt themselves academically also may under-perform as a result. Hence, the hypothesis of stereotype threat by athletes themselves is separate from the alternate hypothesis that faculty attitudes toward athletics can affect the academic performance of student-athletes.

A third alternative hypothesis to the culture of athletics is that other institutional factors have a significant effect on the academic performance of student-athletes. For example practices and games may conflict with review sessions, presentations by visiting lecturers, study group meetings, and other course-related activities. Similarly, if instructors schedule office hours at times that practices usually are scheduled, athletes may have fewer opportunities to come for help than other students. In such cases, more thought by the faculty member and better communication with coaches may be helpful. In my experiences at a Division III institution, coaches I have contacted will often either rearrange their practice schedule or excuse a student-athlete from practice if contacted well in advance and the conflicting academic obligation is significant.

It is important to sort out and assess these different potential explanations, as well as other possible accounts, since each may suggest different strategies for improving the academic performance of athletes. Moreover, these different hypotheses are not incompatible but may all play some explanatory role. One way of assessing their relative merits might involve investigating how well each explains the alleged differences in academic performances between male and female athletes, as well as those between teams and among individual teammates. 
Thus, a hypothesis that assigns significant explanatory power to faculty attitudes toward athletics might need to postulate a perhaps implausible degree of difference in faculty treatment of female and male athletes. But equally, those who stress the explanatory force of the culture of athletics would need to explain why that culture is stronger among teams that perform poorly academically than among teams that perform well, and why many male athletes, even in high profile sports where that culture may be presumed to be strongest, do so well academically. In addition, some independent way to measure the degree of strength of the culture in different contexts is needed so we could establish a correlation between cultural influence and academic performance in the first place. Without an independent test, we would be explaining poor performance by appeal to a culture of athletics but our only evidence that it was present would be the poor performance itself.

In any case, even if the culture of athletics does play an important role in explaining the academic performance gap between student-athletes and other students at the institutions studied, other factors may be at least equally important or may exacerbate its effects significantly. If so, attributing the gap largely to the attitudes, practices, and "culture" of the student-athletes themselves may be unwarranted.

It also is important to note that not all aspects of the culture of athletes, as described by Bowen and Shulman, are negative, although my reading of the book suggests that they are given a negative spin by the authors. Why, for example, is it a bad thing if student-athletes have more conservative values than other students? Indeed, the latter can be viewed as a contribution to intellectual diversity and might well enliven classroom discussion if instructors teaching courses involving political and social analysis encouraged more conservative students to defend their positions in class.

The significance of this for the mutual reinforcement of academics and athletics is that, if there is a significant gap in academic performance between (male) student-athletes and students at large, institutional changes designed to enhance the academic opportunities for athletes, including relatively manageable factors such as giving more consideration to athletic schedules when posting office hours or holding review sessions, may well improve the situation.

My last question about The Game of Life concerns whether it correctly assesses the value of intercollegiate athletics as part of the educational process itself. There is remarkably little discussion of such questions in The Game of Life. While attention is paid to the question of whether athletes contribute more to society than nonathletes after graduation, the issue is framed largely in quantitative terms, involving such questions as comparison of earnings and the success of athletes vs. nonathletes at becoming CEOs.

While such questions are of interest, they do not speak to the question of whether the experiences of athletes on the playing field, and perhaps those of spectators, are of educational value. Do athletes sometimes learn something about themselves or others in trying to meet the challenges of their sport? Does athletics sometimes reveal or illustrate something of value to a wider audience? Does athletics sometimes play a role on campus in building community or illustrating the compatibility of diversity and social union? Thus, if some versions of the Mutual Reinforcement Thesis are correct, or apply to significant segments of intercollegiate athletics, college sports provide kinds of benefits not considered in The Game of Life. 
So although The Game of Life raises issues that should be of concern to those involved in athletics and higher education, its arguments, while clear and thoughtful, are not conclusive. As with any work of substance, it raises further questions that might be explored most fruitfully by both ethicists concerned with sport and social scientists. My own tentative conclusion is that while the conclusions of the book are worrisome and must be taken seriously, they also present too harsh a picture of intercollegiate athletics at many of the institutions studied.

\section{Conclusions and Suggestions}

So what has our discussion suggested about the value of intercollegiate athletics and its compatibility with academic values? Given the diversity of intercollegiate athletic programs and the problems faced at different levels of competition, broad generalizations probably should be avoided. The issues that arise at many of the institutions studied in The Game of Life differ significantly from those facing athletic programs at many large, athletically elite Division I institutions.

In any case, my goal has not been to say everything is fine in intercollegiate athletics. However, I have tried to argue, first, that the picture is far from all bleak and that some of the arguments about the incompatibility of intercollegiate athletics and academic and moral development are not conclusive. Second, I have suggested areas of further research, of the kind that I hope the NCAA Colloquia can encourage, that would help clarify points at issue and perhaps resolve reasonable disagreement in this area. Among these are the extent to which coaches do and should encourage or promote critical thinking among their players, the degree to which evaluations of the moral maturity of athletes may themselves reflect controversial moral assumptions of the investigators, and the extent to which institutional factors other than the culture of athletics inhibit academic performance by student-athletes. In many of these areas, collaborative work or at least greater communication between social scientists and ethicists can contribute to better understanding of these issues.

I also have suggested that a case can be made that values implicit in properly run athletic programs are compatible with and can even reinforce values central to academic inquiry. Moreover, I have argued that some important criticisms of this view are not decisive. While each critical point may have force in particular contexts or at some institutions, it is far from clear that they apply across the board to college athletics. If my discussion has force, then, it suggests there also may be much of value in many segments of intercollegiate athletics and much to be gained by focusing on better integration of athletics and academics.

Does the discussion suggest any concrete ways of promoting harmonization? For one thing, following up on the suggestion of Stoll and Beller that interventions can make a significant difference in the moral development of athletes, participants in intercollegiate athletics might be encouraged to reflect critically on their athletic experiences and the broader significance of athletics in our culture. This might involve formal course work, including the opportunity to take courses on the sociology, psychology, and philosophy of sport, or more informal but still structured exchanges with coaches and academic faculty. One example of such an existing program is the Madison Academic and Athletic Exchange (MAAX) Program at the University of Wisconsin (2008). As described by the University, MAAX is a curriculum-based service-learning initiative in civic engagement that 
brings first-year University of Wisconsin students, including but not restricted to intercollegiate athletes, together with local high school student-athletes for a collaborative inquiry in an English composition course geared to investigating relationships between academics and athletics. I was fortunate enough to speak to these students in the spring of 2007 and was impressed by their engagement and reflection on issues of academics and athletics.

Other forums, both formal and informal, might encourage communication and perhaps better understanding between coaches and other faculty. For example, several years ago my institution supported a series of summer seminar sessions for faculty and coaches on The Game of Life that proved valuable not only for our understanding of the strengths and weaknesses of the book, but also for bringing people from diverse areas of our institution together to discuss common concerns about intercollegiate athletics. Greater contact between coaches and faculty may not only promote better understanding of differing perspectives between both groups but also reduce stereotyping of each group by the other. Such exchanges can encourage coaches to internalize the academic values of their institution, even when they may hinder competitive success. Dialogue also may influence faculty who are uninterested in athletics to appreciate the educational value of athletics as well. J. Douglas Toma makes a similar point in "Share the Goal of Integration" in the NCAA News (Toma, 2007, p. 4ff).

Finally, faculty might be encouraged to play a more proactive role in mentoring student-athletes, particularly first-generation college students during their first two years at the institution, helping them to balance athletic and academic obligations in an appropriate manner and to make a full commitment to academic achievement.

In any case, if I am correct in arguing that a defensible ethic of intercollegiate athletic competition embodies many values that cohere with and are supportive of central academic values, whether at the causal, illustrative, or critical levels, college sports can be and perhaps often are a valuable aspect of the educational experience. I hope further research of the kind the NCAA Colloquia hopes to support can help assess whether such a thesis retains credibility after more extended critical examination.

\section{Notes}

1. The idea of defining games as activities where the constitutive rules create artificial obstacles to challenge us was most influentially developed by Bernard Suits whose informal definition of playing games (sports being games of physical skill) is "the voluntary attempt to overcome unnecessary obstacles" (Suits, as quoted in Morgan, 2007). Suits's conceptual analysis has been a significant influence on later writers seeking to develop normative theories of sport, including my own work in my book, Fair Play: The Ethics of Sport (Simon, 2004), particularly Chapters 2 and 3.

2. An example of this is the duty to play hard to create a challenge for competitors and the right to have competitors respect the rules and principles of the sport. This view also suggests that winning, while an important criterion of success since it ordinarily indicates who best meets the challenge of the competition, is not always such an indicator, as when an athletically superior team ekes out a sloppy victory over a vastly inferior opponent who played its best but fell just short of overcoming the superior athleticism of the winner. In such a contest, the loser may well have met the challenge of competition best by playing to its full potential, whereas the 
winner's play was marred by miscues, lack of effort at key points, and general sloppy execution throughout the contest.

3. For a reply to the view that research on moral development may make some moral assumptions of its own, see Sharon Stoll's 1999 article in the Journal of the Philosophy of Sport "Should Character be Measured? A Reply to Professor Gough and the Reductionist Argument." For a reply to Stoll, see M. Andrew Holowchak (2001), "Can Character be Measured? A Reply to Stoll's Reply to Gough," also in the Journal of the Philosophy of Sport.

4. This section draws heavily upon and expands upon my review of The Game of Life that appeared in the Journal of the Philosophy of Sport XXIX in 2002.

\section{References}

Bowen, W.G., \& Bok, D. (2000). The shape of the river. Princeton: Princeton University Press.

Bowen, W.G., \& Levin, S.A. (2003). Reclaiming the game: College sports and educational values. Princeton: Princeton University Press.

Brand, M. (2006). The role and value of intercollegiate athletics in universities. Journal of the Philosophy of Sport, XXXIII, 9-20.

Bredemeier, B.J., \& Shields, D.L. (1995) Character Development and Physical Activity. Champaign, IL:Human Kinetics.

Bredemeier, B.J., \& Shields, D.L. (2001). Moral growth among athletes and nonathletes: A comparative analysis. The Journal of Genetic Psychology, 147, 15-16.

Barry, B. (1995). Justice as impartiality. New York: Oxford University Press.

Camus, A. (1960). The wager of our generation. In Resistance, rebellion, and death, Trans. J. O'Brien, p.42. New York: Vintage.

French, P. (2004). Ethics and college sports: Ethics, sports, and the university. Lanham, MD: Rowman and Littlefield.

Fullinwider, R. (2006). Sports, youth and character: A critical survey. Working Paper \#44 by CIRCLE (Center for Information and Research on Civic Learning \& Engagement), College Park, MD. Accessed February 2006 at http://www.civicyouth.org/?page_id=152 (It is in pdf form but hasn't a distinct internet address; this link brings up the list of CIRCLE working papers).

Gough, R.W. (1995). On reaching first base with a "science" of moral development in sport: Problems with scientific objectivity and reductivism. Journal of the Philosophy of Sport, XXII, 11-25.

Holowchak, M.A. (2001). Can character be measured? A reply to Stoll's reply to Gough. Journal of the Philosophy of Sport, XXVIII, 103-106.

Hyland, D. (1984). The question of play (pp. 148-151). Lanham, MD: University Presses of America.

Morgan, W.J., Ed. (2007). Ethics in sport. Champaign, IL: Human Kinetics.

Putnam, R.D. (2000) Bowling Alone. The collapse and revival of American community. New York: Simon and Schuster.

Shulman, J.L., \& Bowen, W.G. (2001). The game of life: College sports and educational values. Princeton: Princeton University Press.

Simon, R.L. (2002). Review of The Game of Life. Journal of the Philosophy of Sport, XXIX, $87-95$.

Simon, R.L. (2004). Fair play: The ethics of sport. Boulder: Westview.

Stoll, S. (1999) Should character be measured? A reply to Professor Gough and the reductionist argument. Journal of the Philosophy of Sport, XXVI, 95-104.

Stoll, S.K., \& Beller, J.M. (2000). Do sports build character? In J Gerdy (Ed.), Sports in school: The future of an institution. New York: Columbia University Press. 
Suits, B. (1973). The Elements of sport. In R. Osterhoudt, Ed., The philosophy of sport: A collection of essays (pp. 48-64). Springfield, IL: Charles C. Thomas.

Toma, J.D. (2007). Share the goal of integration. NCAA News, 44 (Nov. 5, 2007), $4 \mathrm{ff}$.

University of Idaho Center for Ethics. (2008). Measurement tools: The Hahm Beller values choice inventory. Accessed April 21, 2008, at www.educ.uidaho.edu/center_for_ethics/ Measurements/hbvci.htm

University of Wisconsin. (2008). MAAX Program. Accessed May 13, 2008, at www.humanities.wisc.edu/assets/aux/maax

Weiss, P. (1969). Sport, a philosophic inquiry. Carbondale, IL: Southern Illinois University Press.

Wilson, J.Q. (2007, October). Bowling with Others. Commentary, 124, 31. 